\title{
Temporal profiles of vegetation indices for characterizing grazing intensity on natural grasslands in Pampa biome
}

\author{
Amanda Heemann Junges ${ }^{1 *}$, Carolina Bremm ${ }^{1}$, Denise Cybis Fontana ${ }^{2}$, Carlos Alberto Oliveira de Oliveira ${ }^{1}$, Laura Pigatto \\ Schaparini², Paulo César de Faccio Carvalho ${ }^{2}$
}

${ }^{1}$ Agricultural and Livestock Research Foundation, R. Gonçalves Dias, 570 - 90130-060 - Porto Alegre, RS Brazil.

${ }^{2}$ Federal University of Rio Grande do Sul - Dept. of Forage Plant and Agrometeorology, Av. Bento Gonçalves, 7200, C.P. 15100 - 91450-000 - Porto Alegre, RS - Brazil.

*Corresponding author <amandahj@hotmail.com>

Edited by: James Pierre Muir

Received May 18, 2015

Accepted October 21, 2015
ABSTRACT: The Pampa biome is an important ecosystem in Brazil that is highly relevant to livestock production. The objective of this study was to analyze the potential use of vegetation indices to discriminate grazing intensities on natural grasslands in the Pampa biome. Moderate Resolution Imaging Spectroradiometer (MODIS) Normalized Difference Vegetation Index (NDVI) and Enhanced Vegetation Index (EVI) images from Jan to Dec, 2000 to 2013 series, were analyzed for natural grassland experimental units managed under high (forage allowance of $5 \pm 2 \%$ live weight - LW), moderate $(13 \pm 5 \%$ LW) and low grazing intensity $(19 \pm 7 \%$ LW). Regardless of intensity, the temporal profiles showed lower NDVI and EVI during winter, increased values in spring because of summer species regrowth, slightly decreased values in summer, especially in years when there is a water deficit, and increased values in the fall associated with the beginning of winter forage development. The average temporal profiles of moderate grazing intensity exhibited greater vegetation index values compared with low and high grazing intensities. The temporal profiles of less vegetation index were associated with lower green biomass accumulation caused by the negative impact of stocking rates on the leaf area index under high grazing intensity and a floristic composition with a predominance of tussocks under low grazing intensity. Vegetation indices can be used for distinguishing moderate grazing intensity from low and high intensities. The average EVI values can discriminate moderate grazing intensity during any season, and the NDVI values can discriminate moderate grazing intensity during spring and winter.

Keywords: MODIS, NDVI, EVI, green biomass, stocking rate

\section{Introduction}

The Pampa biome is an important ecosystem in Brazil which has great relevance to livestock production. With the growing impact of overgrazing, this natural resource has become seriously threatened (Carvalho and Batello, 2009). The sustainable use of grassland areas has high environmental and socio-economic relevance because animal production on degraded grasslands is less than that on restored or well-managed grasslands. In production systems, adjusting grazing intensity according to the forage allowance is vital for achieving sustainability; however, this process is subjective and depends on the evaluator's experience. Therefore, rapid and effective grazing intensity monitoring over large areas is central to the conservation of natural grasslands in the Pampa biome.

Satellite imagery provides an important data source for monitoring vegetation cover dynamics because it generates objective information with adequate spatial and temporal characteristics (Li et al., 2012). The Normalized Difference Vegetation Index (NDVI) and the Enhanced Vegetation Index (EVI) are considered indicators of plant growth and can be employed in the determination of correlated biophysical variables, such as the leaf area index (LAI), biomass, photosynthetic activity and grain yields (Xavier et al., 2006; Fernandes et al., 2011; Monteiro et al., 2012).

Monitoring the Pampa biome using spectral information has been the objective of studies (Wagner et al.,
2013) that have focused on regional soil-plant-atmosphere relationships. However, a limited number of studies have evaluated the temporal behavior of natural grasslands under different grazing intensities and have addressed the influence of management on the definition of vegetation dynamics. Regular observations of grassland conditions using vegetation indices can be employed to monitor biomass and can assist in management decisions that benefit species composition and forage production during livestock husbandry (Li et al., 2012), thus helping reconcile the conservation vs production dilemma (Carvalho and Batello, 2009).

Given the essentiality of monitoring primary productivity to adjust grazing intensity on natural grasslands, the objectives of this study were i) to characterize the temporal evolution of natural grasslands in the Pampa biome managed under different grazing intensities using Moderate Resolution Imaging Spectroradiometer (MODIS) sensor NDVI and EVI and ii) to analyze the potential use of vegetation indices to discriminate seasonal patterns of grazing intensities on natural grasslands in the Pampa biome.

\section{Materials and Methods}

\section{Study area}

This study covered an area of 64 ha of natural grassland in the central depression region of the state of Rio Grande do Sul, Brazil (3006'06" S, 51 40'59" W and 
$46 \mathrm{~m})$. According to the Köppen classification system, the climate of the region is Cfa, which is humid subtropical, and the average temperatures in the hottest month are above $22^{\circ} \mathrm{C}$. Total annual precipitation is $1,455 \mathrm{~mm}$ and is well distributed throughout the year - monthly totals are between $102 \mathrm{~mm}$ (Mar) and $154 \mathrm{~mm}$ (June). Average monthly temperatures vary between $13^{\circ} \mathrm{C}$ (July) and $24^{\circ} \mathrm{C}(\mathrm{Jan})$, and the daily average global solar radiation is $360 \mathrm{cal} \mathrm{cm}^{2} \mathrm{~d}^{-1}$. The experimental area presents a slightly undulating relief. Soils are classified as Hapludult and Plinthudult type, and are used as blocking factors.

This long-term experiment has been conducted since 1986. Beef cattle graze experimental paddocks throughout the year in a continuous stocking system. Contrasting grazing intensities have been applied by treatments based on daily forage allowance levels. The protocol includes treatments of 4, 8, 12, and $16 \mathrm{~kg}$ of dry matter (DM) per $100 \mathrm{~kg}$ of live weight (LW) (kg DM 100 $\mathrm{kg} \mathrm{LW} \mathrm{LW}^{-1}$ or $\% \mathrm{LW}$ ) fixed throughout the year in addition to annual variable allowances: 8 to $12 \%(8 \%$ in spring and $12 \%$ the rest of the year), 12 to $8 \%$ (12\% in spring and $8 \%$ the rest of the year) and 16 to $12 \%$ (16\% in spring and $12 \%$ the rest of the year). Forage allowance is the relationship between forage mass and animal live weight per unit area of the specific unit of land being grazed at any one time; and is considered an instantaneous measurement of the forage-to-animal relationship (Allen et al., 2011). This concept requires continuous stocking rate adjustments to the targeted forage allowance as pastures grow.

The experimental animals were beef heifers crossed between Angus, Hereford and Nellore breeds with a live weight of $245 \pm 39 \mathrm{~kg}$, which were allocated annually to the experimental units. The use of natural grasslands with forage allowance management promoted the formation of two distinct strata: a lower stratum that is comparatively uniform with a greater presence of green leaves and species with a prostrate or rhizomatous growth habit, such as Paspalum notatum Flügge and Axonopus affinis Chase, and an upper stratum comprising tufted species, such as Andropogon lateralis Ness, Aristida jubata (Arechav) Herte and Aristida laevis Ness, which are found in treatments with higher forage allowances (Cruz et al., 2010).

The experimental units (EUs) were not subject to other types of human interventions apart from adjustments in grazing intensity. In this study, the experimental areas were demarcated using a Global Positioning System (GPS) based on a pixel grid of MODIS sensor images with $250 \mathrm{~m}$ spatial resolution (Figure 1). The EUs of the forage allowances were classified into three nominal grazing intensity treatments to obtain high (EUs with a $4 \%$ forage allowance), moderate (EUs with $8,12,8$ to 12 and 12 to 8 $\%$ forage allowances), and low (EUs with 16 and 16 to 12 $\%$ forage allowances) grazing intensity vectors. The average forage allowances ( \pm standard deviation) in the high, moderate and low grazing intensity treatments were $5 \pm$ $2 \%, 13 \pm 5 \%$, and $19 \pm 7 \%$, respectively.

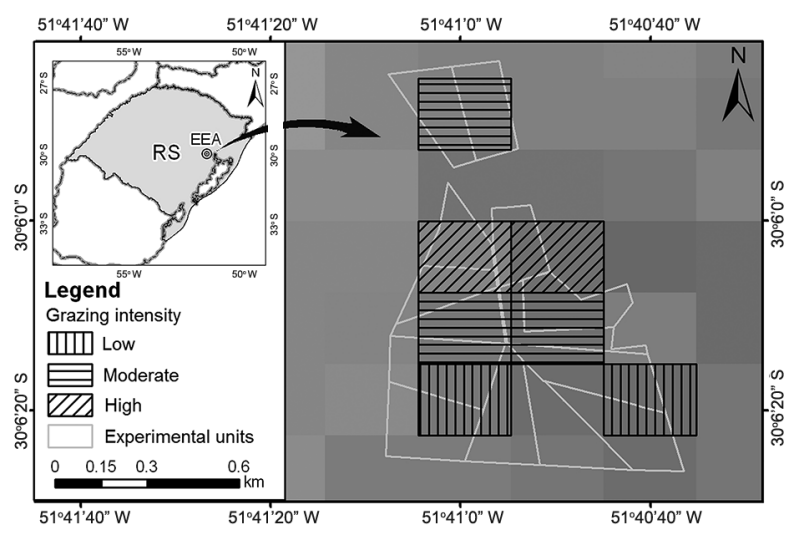

Figure 1 - Location of study area and experimental units related to low, moderate and high grazing intensities on natural grassland in the Pampa biome, with delimitation of pixel grid of MODIS (Moderate Resolution Imaging Spectroradiometer) sensor images. RS: Rio Grande do Sul State, Brazil; EEA: Experimental Agronomy Station.

\section{NDVI and EVI MODIS sensor images}

The experimental grazing intensity areas were characterized by the temporal evolution of the vegetation indices NDVI and EVI. Images from the MODIS sensor (product MOD13Q1, collection 5) from Jan to Dec, series 2000 to 2013, were used for a total of 319 images. Specifically in 2000, images from Feb $2^{\text {nd }}$ to Dec were used because of MODIS image availability. The MODIS images for the vegetation indices corresponded to the maximum-value composition every 16 days (temporal resolution). The vectors of the areas corresponding to EUs with high, moderate and low grazing intensities were superimposed on NDVI and EVI images to extract average biweekly values for NDVI and EVI for each treatment and year.

\section{Analysis}

The NDVI and EVI temporal profiles from Jan to Dec, 2000 to 2013, were developed for the three grazing intensity treatments based on the average values of the vegetation indices in each MODIS image. To characterize the vegetation growth and green biomass accumulation throughout the year, the average temporal profile of natural grasslands in the Pampa biome was defined based on the average values of the vegetation indices in the analyzed series, independent of the grazing intensity ( $\mathrm{n}=2,233)$.

The ability of the MODIS vegetation indices NDVI and EVI to determine grazing intensities and seasons was evaluated using statistical analysis. The average values for the seasonal vegetation index referred to the average NDVI/EVI of biweekly periods corresponding to the season as follows: spring (Sept $2^{\text {nd }}$ to Dec $1^{\text {st }}$ ); summer (Dec $2^{\text {nd }}$ to Mar $1^{\text {st }}$ ); fall (Mar $2^{\text {nd }}$ to June $1^{\text {st }}$ ); and winter (June $2^{\text {nd }}$ to Sept $1^{\text {st }}$. The vegetation indices 
NDVI and EVI were analyzed separately using an analysis of variance (ANOVA) at a $5 \%$ significance level. The model included fixed effects for the treatment, season, and treatment*season interaction; it included random effects for the block, year, and season*year interaction. Differences between the averages were compared using Tukey's test at the same significance level ( $p \leq 0.05)$. JMP statistical software (version 10, SAS Institute) was used.

\section{Results and Discussion}

The temporal profiles of the vegetation indices NDVI and EVI are consistent with the temporal evolution of the biomass on natural grasslands in the Pampa biome and corroborating studies that have used indices to characterize vegetation in the state of Rio Grande do Sul or in individual regions of the Pampa biome (Wagner et al., 2013). NDVI and EVI can discriminate moderate from high and low grazing intensities. The ability to discriminate moderate grazing intensity becomes important for monitoring natural grasslands in the Pampa biome because management is necessary for the sustainability of these grasslands. Studies conducted over 25 years on natural grasslands indicate that moderate grazing intensity (12 kg DM $100 \mathrm{~kg} \mathrm{LW}^{-1}$ ) benefits animal and plant production (Carvalho, 2013).

\section{Average temporal profiles of natural grasslands in the Pampa biome}

The NDVI and EVI temporal profiles obtained in this study (Figure 2) indicated that average NDVI values varied between 0.61 (winter) and 0.68 (summer/fall), and the EVI values varied between 0.34 (winter) and 0.41 (summer) (Figure 2). The lowest NDVI and EVI values occurred in winter because of reduced available solar radiation and air temperature which reduce the impact on plant biomass growth and accumulation; therefore, winter is considered the most limiting period for animal production on native grasslands in southern Brazil (Mezzalira et al., 2012). The index values increased starting on Sept $2^{\text {nd }}$ and reached 0.65 for NDVI and 0.41 for EVI on Dec $2^{\text {nd }}$, which adequately characterizes the regrowth period for summer grasses, particularly Paspalum notatum, Andropogon lateralis, Axonopus affinis and Aristida spp. (Cruz et al., 2010). This result is consistent with studies that identify spring as the highest live weight gain period for livestock because of the greater availability of food from biomass accumulation of summer forage species (Neves et al., 2009).

In summer, especially during January, the temporal profiles of both indices exhibited a drop in values (0.64 for NDVI and 0.39 for EVI), although these values remained higher than the values in winter. Using NDVI and EVI MODIS images from 13 regions in the Pampa biome, which has a distinct botanical composition and soils, Wagner et al. (2013) found that January had the greatest inter-annual variability in vegetation index values, especially for NDVI. The reduction in NDVI and

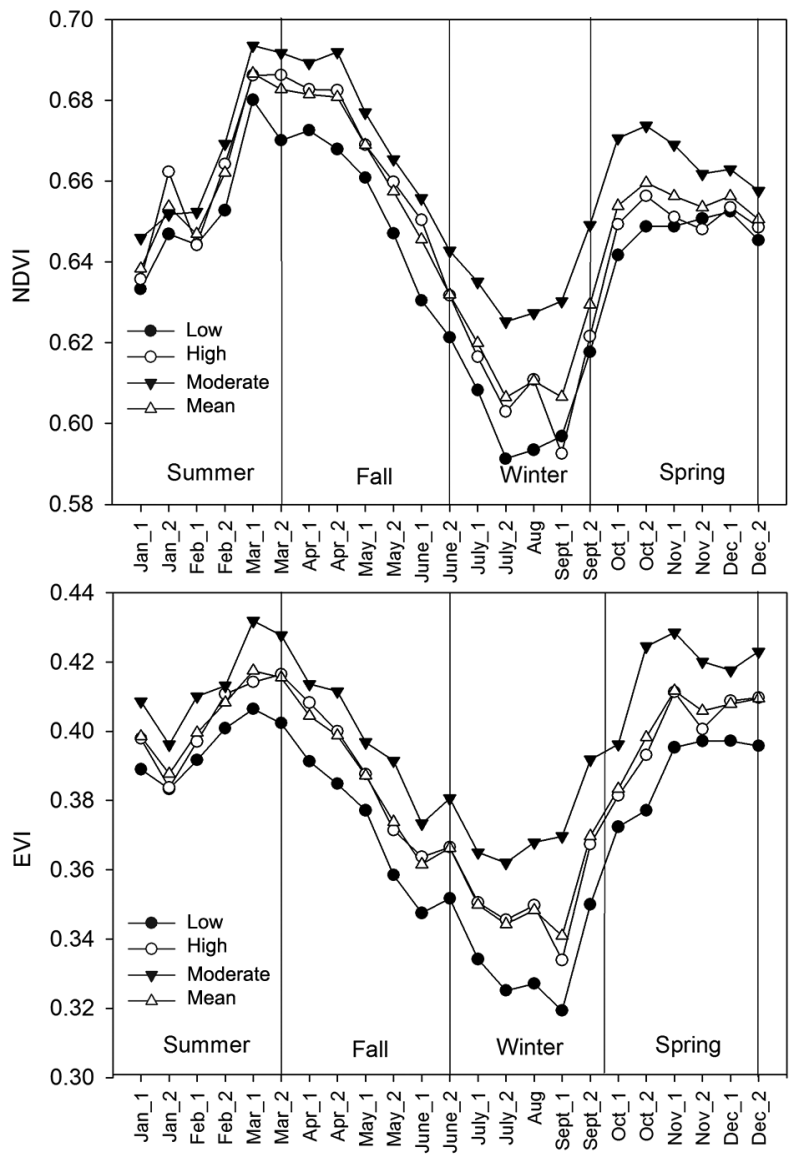

Figure 2 - Average temporal profiles of Normalized Difference Vegetation Index (NDVI) and Enhanced Vegetation Index (EVI) on natural grassland in the Pampa biome, Brazil, managed under grazing intensities (high, low and moderate), series 2000 to 2013.

EVI values in average temporal profiles most likely occurred in years characterized by droughts in the state during the spring-summer period. In these years, water deficits could have reduced biomass accumulation by forage species.

The average NDVI and EVI temporal profiles exhibited further increases in index values between the end of summer and the beginning of autumn, with maximum recorded values of 0.41 and 0.68 for EVI and NDVI, respectively. The increased values, independent of the vegetation index, could be associated with the vegetation growth resulting from an adequate water supply because of the lower evaporative demand from the atmosphere in fall and winter as well as with the beginning of growth and development of winter forage species, such as Piptochaetium montevidense Spreng., which are found in greater proportions in the experimental area /Cruz et al., 2010).

The NDVI and EVI temporal profiles obtained in this study (Figure 2) were determined from spectral information from a reduced set of pixels due to the area of 
the experimental units. Paddocks ranged between 3.0 and $5.2 \mathrm{ha}$, whilst the spatial resolution of the MODIS images was 6.25 ha. Consequently, only two or three pixels were employed to address each grazing intensity. Ferreira et al. (2006) employed 10 pixels for each class of NDVI and EVI images to study natural and converted landscapes of the Cerrado. In this study, the reduced set of pixels was largely compensated for by making use of 14 years of image data (319 images) representing satisfactorily the targeted temporal profiles and corroborate the results of Wagner et al. (2013). Adami et al. (2008) employed 139 images of MODIS vegetation indices in the study of spatial-temporal dynamics of the Pantanal biome. The MODIS images can support the effective and systematic monitoring of vegetation to perform landscape analysis on a multi-temporal scale, allowing for the characterization of the biomes by their ecological function and human intervention levels (Ferreira et al., 2006). Thus, MODIS images provide a source of free information for monitoring and developing grassland vegetation that can benefit conservation initiatives in the Pampa biome.

\section{Average and seasonal temporal profiles for NDVI and EVI under different grazing intensities}

An analysis of the average temporal profiles of the vegetation indices under different grazing intensities (Figure 2) indicated that the values were higher for moderate grazing intensity. At low and high intensities, the values were comparatively less, and no significant differences were observed between these treatments. Lower vegetation index values in grasslands managed under high grazing intensity were expected because of reduced sward height and biomass (Mezzalira et al., 2012; Figure 3A) due to the negative impact of stocking rates on the LAI (Carvalho and Batello, 2009). Therefore, the grassland resembles a lawn at high intensity, with a predominance of prostrate summer species and a greater proportion of exposed soil (Cruz et al., 2010).

Low grazing intensity, in turn, resulted in increased sward height (Holland et al., 2008; Da Trindade et al., 2012), which could be related to greater green biomass values and greater NDVI and EVI values. However, greater vegetation indices do not occur under low grazing intensity, which demonstrated that the floristic composition of this pasture reduces green biomass accumulation. According to Cruz et al. (2010), low grazing intensity supports the growth of species with less relative growth; these species are characterized by typical resource-conserving strategies and the formation of tussocks, such as species belonging to the genus Aristida spp. and Andropogon spp., which are characterized by prolonged nutrient residence times in the leaves and high levels of fiber. The percent cover of tussocks in areas managed under low grazing intensity in natural grasslands reaches values of approximately $44 \%$ (Mezzalira et al., 2012), and these tussocks exhibit high levels of DM and accumulated senescent material (Figure 3B).

The analysis of the average seasonal vegetation index data indicated that there was an interaction between treatment and season for NDVI ( $p=0.0081$ ) (Table 1). The average NDVI under low grazing intensity was less in winter and was distinct from the values observed during other seasons. In winter, the NDVI values for grasslands managed under low grazing intensity did not differ from those observed in high-intensity grasslands, demonstrating that neither type of management favors green biomass accumulation and that low and high grazing intensities provide low high-quality forage allowances for animals. In turn, it was possible to discriminate moderate grazing intensity in winter and spring, which are periods when the NDVI values at this grazing intensity were higher than those at other intensities. The ability to discriminate moderate grazing intensity is important for monitoring natural grasslands in the Pampa biome because the highest values of individual and per-area animal performance are obtained at this intensity (Mezzalira et al., 2012).

In summer, it was not possible to discriminate between grazing intensities; this period was associated with a reduction in NDVI values in years characterized by droughts in the state, and average NDVI values at moderate grazing intensity were similar to those ob-
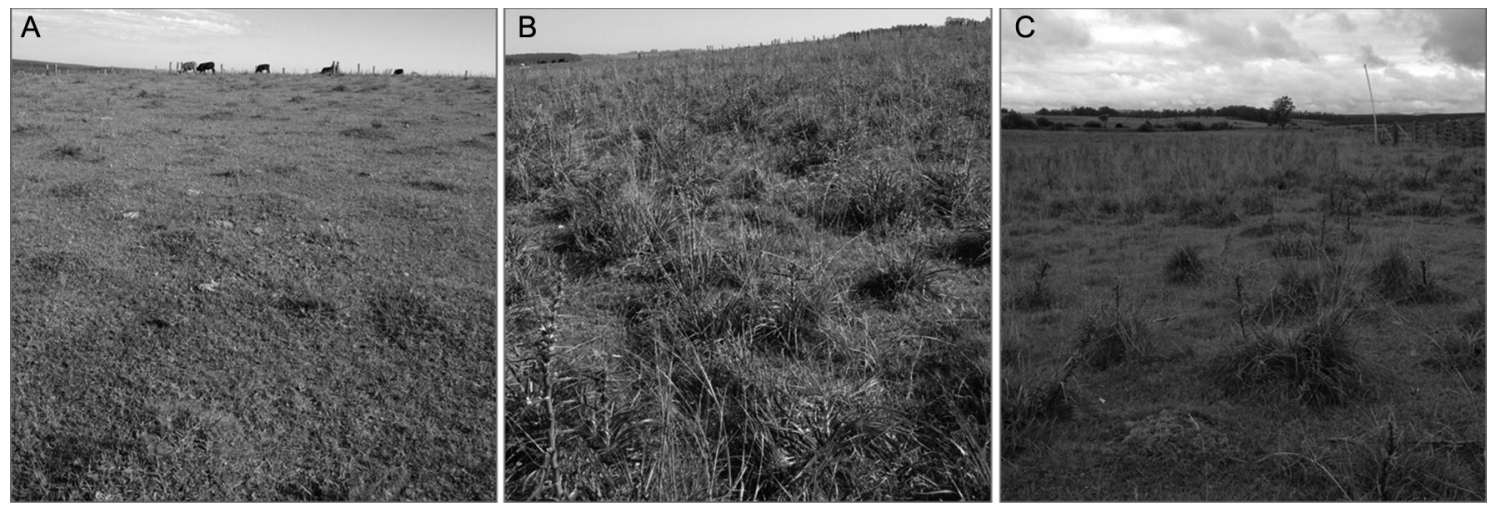

Figure 3 - Characterization of natural grassland in the Pampa biome, Brazil, managed under grazing intensities: high (A), low (B) and moderate (C). 
Table 1 - Seasonal average values of Normalized Difference Vegetation Index (NDVI) and Enhanced Vegetation Index (EVI) in low, moderate and high grazing intensities on natural grassland in the Pampa biome, Brazil, series 2000 to 2013.

\begin{tabular}{|c|c|c|c|c|}
\hline \multirow{3}{*}{ Season } & \multicolumn{3}{|c|}{ Grazing intensity } & \multirow{2}{*}{ Average \pm SD } \\
\hline & High & Moderate & Low & \\
\hline & \multicolumn{4}{|c|}{ NDVI } \\
\hline Summer & $0.65 \mathrm{Aa}$ & $0.66 \mathrm{ABa}$ & $0.65 \mathrm{Aa}$ & $0.656 \pm 0.06$ \\
\hline Fall & $0.66 \mathrm{Aab}$ & $0.67 \mathrm{Aa}$ & $0.66 \mathrm{Ab}$ & $0.670 \pm 0.05$ \\
\hline Winter & $0.60 \mathrm{Bb}$ & $0.63 \mathrm{Ba}$ & $0.60 \mathrm{Bb}$ & $0.615 \pm 0.05$ \\
\hline Spring & $0.64 \mathrm{ABb}$ & $0.66 \mathrm{ABa}$ & $0.64 \mathrm{Ab}$ & $0.656 \pm 0.05$ \\
\hline Average & 0.64 & 0.65 & 0.64 & $0.651 \pm 0.06$ \\
\hline \multicolumn{5}{|c|}{ EVI } \\
\hline Summer & 0.39 & 0.41 & 0.40 & $0.403 \pm 0.06 \mathrm{~A}$ \\
\hline Fall & 0.38 & 0.40 & 0.38 & $0.390 \pm 0.06 \mathrm{~A}$ \\
\hline Winter & 0.34 & 0.36 & 0.33 & $0.349 \pm 0.06 \mathrm{~B}$ \\
\hline Spring & 0.38 & 0.41 & 0.38 & $0.396 \pm 0.05 \mathrm{~A}$ \\
\hline Average & $0.37 b$ & $0.34 \mathrm{a}$ & $0.37 \mathrm{~b}$ & $0.388 \pm 0.06$ \\
\hline
\end{tabular}

Different letters, lowercase within a line and uppercase within a column, indicate significant differences by Tukey's test ( $p \leq 0.05)$; SD: standard deviation.

served at other intensities. In the fall, which was characterized by the development of winter forage species, it was only possible to discriminate between moderate and low grazing intensity. At high grazing intensity, the accumulation of green biomass during this season was similar to that accumulated at moderate intensity in terms of NDVI, which was inconsistent with what occurred in other seasons. This result highlights the growth potential of pasture in fall under high and moderate intensities and the management practices that promote forage accumulation in the fall, including the adoption and deferral of grazing intervals, which can favor available forage for animals in winter (Lemaire et al., 2009).

Analysis of the average EVI data over different seasons indicated that there was no interaction between treatment and season $(p>0.05)$. The EVI values in winter were different from those observed over other seasons, and moderate grazing intensity can be discriminated from high and low intensities regardless of the season.

For the evaluated natural grasslands, the ability to discriminate moderate grazing intensity in any season using the EVI vegetation index can be associated with the sensitivity of EVI to the canopy structure. EVI was developed to optimize the vegetation signal, reduce interference from the canopy background signal and improve the sensitivity of the index under high biomass conditions, whereas NDVI is more sensitive to the presence of photosynthetic pigments, particularly to chlorophyll content (Huete et al., 2002). Because NDVI values above 0.67 were not reached in this study, a saturation trend was not observed, which would reduce the sensitivity of this index in terms of detecting green biomass under high LAI conditions. Thus, the ability to discriminate moderate grazing intensity in all seasons using EVI may be possibly associated with the grasslands' canopy structure (Figure 3C), which comprises the following two well-defined strata (Overbeck et al., 2007): the lower stratum, which is formed by intensively grazed, prostate species, and the upper stratum, which occupies approximately $27 \%$ of the area (Neves et al., 2009) and is dominated by cespitose species of low nutritional value that are rejected by animals, such as Eryngium spp.

\section{Conclusion}

Vegetation indices from MODIS images can be used to characterize green biomass temporal evolution of natural grasslands in the Pampa biome, and they adequately reflect the interactions of climate-plant-animal relationship. The average temporal profiles at moderate grazing intensity (forage allowance from 8 to $12 \%$ LW) exhibited higher vegetation index values compared to low and high grazing intensities. The EVI can be used to discriminate between moderate grazing intensity and low and high grazing intensities during any season, whereas NDVI is more suitable for spring and winter seasons.

\section{Acknowledgements}

This research was financially supported by the Brazilian National Council for Scientific and Technological Development (CNPq) project 482291/2012-5 and by Rio Grande do Sul State Research Foundation (FAPERGS), project 2291-2551/14-4.

\section{References}

Adami, M.; Freitas, R.M.; Padovani, C.R.; Shimabukuro, Y.E.; Moreira, M.A. 2008. Spatial-temporal analysis of MODIS image applied to dynamics of Pantanal biome. Pesquisa Agropecuária Brasileira 43: 1371-1378 (in Portuguese, with abstract in English).

Allen, V.G.; Batello, C.; Berretta, E.J.; Hodgson, J.; Kothmann, M.; Li, X.; McIvor, J.; Mine, J.; Morris, C.; Peeters, A.; Sanderson, M. 2011. An international terminology for grazing lands and grazing animals. Grass and Forage Science 66: 2-28. 
Carvalho, P.C.F.; Batello, C. 2009. Access to land, livestock production and ecosystem conservation in the Brazilian Campos biome: the natural grasslands dilemma. Livestock Science 120: 158-162.

Carvalho, P.C.F. 2013. Harry Stobbs Memorial Lecture: can grazing behavior support innovations in grassland management? Tropical Grasslands - Forrajes Tropicales 1:137-155.

Cruz, P.; Quadros, F.L.F.; Theau, J.P.; Frizzo, A.; Jouany, C.; Duru, M.; Carvalho, P.C.F. 2010. Leaf traits as functional descriptors of the intensity of continuous grazing in native grasslands in the south of Brazil. Rangeland Ecology \& Management 63: 350358.

Da Trindade, J.K.; Pinto, C.E.; Neves, F.P.; Mezzalira, J.C.; Bremm, C.; Genro, T.C.M.; Tischler, M.R.; Nabinger, C.; Gonda, H.L.; Carvalho, P.C.F. 2012. Forage allowance as a target of grazing management: implications on grazing time and forage searching. Rangeland Ecology \& Management 65: 382-393.

Fernandes, J.L.; Rocha, J.V.; Lamparelli, R.A.C. 2011. Sugarcane yield estimates using time series analysis of spot vegetation images. Scientia Agricola 68: 139-146.

Ferreira, M.E.; Ferreira, L.G.; Huete, A.R.; Peccinini, A.A. 2006. Comparative analysis of MODIS products for Cerrado biome biophysical monitoring. Revista Brasileira de Geofísica 24: 251260 (in Portuguese, with abstract in English).

Holland, J.P.; Waterhouse, A.; Robertson, D.; Pollock, M.L. 2008. Effect of different grazing management systems on the herbage mass and pasture height of a Nardus stricta grassland in western Scotland, United Kingdom. Grass and Forage Science 63: 48-59.

Huete, A.R.; Didan, K.; Miura, T.; Rodriguez, E.P.; Gao, X.; Ferreira, G. 2002. Overview of the radiometric and biophysical performance of the MODIS vegetation indices. Remote Sensing of Environment 83: 195-213.
Lemaire, G.; Da Silva, S.C.; Agnusdei, M.; Wade, M.; Hodgson, J. 2009. Interactions between leaf lifespan and defoliation frequency in temperate and tropical pastures: a review. Grass and Forage Science 64: 341-353.

Li, S.; Potter, C.; Hiatt, C. 2012. Monitoring of net primary production in California rangelands using Landsat and MODIS satellite remote sensing. Natural Resources 3: 56-65.

Mezzalira, J.C.; Carvalho, P.C.F.; Da Trindade, J.K.; Bremm, C.; Fonseca, L.; Amaral, M.F.; Reffatti, M.V. 2012. Animal and vegetal production of a natural pasture under different forage allowances for cattle. Ciência Rural 42: 1264-1270 (in Portuguese, with abstract in English).

Monteiro, P.F.C.; Angulo Filho, R.; Xavier, A.C.; Monteiro, R.O.C. 2012. Assessing biophysical variable parameters of bean crop with hyperspectral measurements. Scientia Agricola 69: 87-94.

Neves, F.P.; Carvalho, P.C.F; Nabinger, C.; Jacques, A.V.A.; Carassai, I.J.; Tentardini, F. 2009. Herbage allowance management strategies to raise beef heifers on natural pastures. Revista Brasileira de Zootecnia 38: 1532-1542 (in Portuguese, with abstract in English).

Overbeck, G.E.; Muller, S.C.; Fidelis, A.; Pfadenhauer, J.; Pillar, V.D.; Blanco, C.C.; Boldrini, I.I.; Both, R.; Forneck, E.D 2007. Brazil's neglected biome: the south Brazilian Campos. Plant Ecology, Evolution and Systematics 9: 101-116. Xavier, A.C.; Rudorff, B.F.T.; Moreira, M.A.; Alvarenga, B.S; Freitas, J.G.; Salomon, M.V. 2006. Hyperspectral field reflectance measurements to estimate wheat grain yield and plant height. Scientia Agricola 63: 130-138.

Wagner, A.P.; Fontana, D.C.; Fraisse, C.; Weber, E.; Hasenack, H. 2013. Temporal trends of vegetation indices on Pampa grasslands in Brazil and Uruguay. Pesquisa Agropecuária Brasileira 48: 1192-1200 (in Portuguese, with abstract in English). 